\title{
Acute HIV Infection among Pregnant Women in Malawi
}

\author{
Cynthia L. Gay, MD, MPHa , Victor Mwapasa, MBBS, MPH, PhD ${ }^{b}$, David M. Murdoch, MD, \\ MPHC $^{\mathrm{C}}$, Jesse J. Kwiek, PhD ${ }^{\mathrm{f}}$, Susan A. Fiscus, PhD ${ }^{\mathrm{e}}$, Steven R. Meshnick, MD, PhD ${ }^{\mathrm{b}}, \mathrm{d}, \mathrm{e}$, \\ and Myron S. Cohen, MD ${ }^{a}, e$ \\ aDepartment of Medicine, University of North Carolina School of Medicine, USA \\ bepartment of Community Health, Malawi-Liverpool-Wellcome Clinical Research Programme, \\ College of Medicine, Blantyre, Malawi \\ 'Department of Medicine, Duke University, USA \\ ${ }^{\mathrm{d} D e p a r t m e n t}$ of Epidemiology, University of North Carolina Gillings School of Global Public Health, \\ USA \\ eDepartment of Microbiology and Immunology, University of North Carolina School of Medicine, \\ USA
}

\begin{abstract}
Introduction-There are limited data on acute HIV infection (AHI) prevalence during pregnancy.

Methods-Malawian pregnant women admitted in the third trimester and meeting eligibility criteria underwent dual HIV rapid antibody testing. AHI prevalence was retrospectively detected through HIV RNA pooling of seronegative plasma.

Results-Among 3825 pregnant women screened, dual HIV rapid testing indicated that $30.2 \%$ were HIV positive, $69.7 \%$ were HIV negative and $0.1 \%$ were indeterminate. Sensitivity and specificity of dual rapid testing was $99.0 \%$ and $98.7 \%$, respectively. Of 2666 seronegative specimens, 2327 had samples available for HIV RNA pooling; 5 women $(0.21 \%)(95 \%$ CI: $0.03,0.40 \%)$ had AHI with a median peripartum viral load of 1,324,766 copies $/ \mathrm{mL}$.

Discussion-Pregnant women are at risk for AHI, warranting counseling of all women and their sexual partners about incident HIV during pregnancy. Dual HIV rapid tests have high sensitivity and specificity. HIV testing should be repeated in the third trimester and/or at delivery.
\end{abstract}

\section{Keywords}

Acute HIV infection; pregnancy; mother to child transmission; rapid HIV testing

\footnotetext{
(c) 2009 Elsevier Inc. All rights reserved.

Address all Reprint Requests and Correspondence to: Cynthia Gay, MD, MPH, University of North Carolina at Chapel Hill, Department of Medicine, Division of Infectious Diseases, CB\# 7030, 130 Mason Farm Road, 2112 Bioinformatics Building, UNC Chapel Hill, Chapel Hill, NC, 27599-7030. Office: 919.843.2726. Fax: 919.966.8928. cynthia_gay@ med.unc.edu. .

${ }_{\mathrm{f}}$ Current Address: Division of Infectious Diseases \& Department of Microbiology, The Ohio State University, USA

Potential Conflicts of Interest: No conflicts.

Publisher's Disclaimer: This is a PDF file of an unedited manuscript that has been accepted for publication. As a service to our customers we are providing this early version of the manuscript. The manuscript will undergo copyediting, typesetting, and review of the resulting proof before it is published in its final citable form. Please note that during the production process errors may be discovered which could affect the content, and all legal disclaimers that apply to the journal pertain.
} 


\section{Introduction}

In the absence of antiretroviral therapy (ART) or prophylaxis, the risk of HIV transmission from mother to child is approximately $15-20 \%$ in Europe, $15-30 \%$ in the United States (US) and 25-35\% in Africa (The Working Group on MTCT of HIV, 1995, Volmink et al., 2007). Although these transmission rates have improved with the introduction of antiretroviral therapy for the prevention of mother to child transmission (PMTCT), only a minority of women receive PMTCT (WHO, 2008). The Joint United Nations Programme on HIV/AIDS (UNAIDS) estimates that the percent of HIV positive Malawian pregnant women and their infants who received ART for PMTCT increased from 5\% in 2005 to $26 \%$ in 2007 (http://data.unaids.org/pub/Report/2008/malawi_2008_country_progress_report_en.pdf). Accordingly, HIV-attributable mortality rates in sub-Saharan Africa for children under the age of five have exceeded 30 per 1000 (Volmink et al., 2007). Since the greatest risk of mother to child transmission (MTCT) occurs during the intrapartum period (Mock et al., 1999), understanding associated factors which are amenable to intervention remains crucial.

Maternal plasma HIV RNA level is a strong independent risk factor for MTCT (John and Kreiss, 1996, John et al., 2001, Khouri et al., 1995). In the study by John and colleagues, HIV transmission risk was $9 \%$ for women with viral loads $<10,000$ copies $/ \mathrm{mL}$ compared with $45 \%$ among women with viral loads above the median of 43,000 copies $/ \mathrm{mL}$; women with viral loads above the median had a four-fold higher risk of transmission (95\% confidence interval (CI), 2.2-7.2). Accordingly, since the highest viral burden in blood and genital secretions is detected during the ramp-up phase of viremia in acute HIV infection (AHI) (Pilcher et al., 2001), AHI during pregnancy may carry a high risk of MTCT HIV transmission. In one study, HIV shedding into cervicovaginal fluid reached levels observed in chronically infected patients within 3 to 5 weeks of symptoms consistent with acute retroviral syndrome (Pilcher et al., 2001). Further, in another study each one log increase in mean HIV-1 DNA titer in cervicovaginal secretions was associated with a higher risk of vertical transmission (odds ratio (OR), 2.28; 95\% CI, 1.09-4.78; $\mathrm{p}=.03$ ) (Tuomala et al., 2003).

Few studies have evaluated the incidence of AHI among pregnant women, particularly in areas of high HIV prevalence such as Malawi, as the detection of AHI requires additional testing to detect HIV RNA or p24 antigen in antibody negative subjects. However, most resource poor settings utilize only rapid HIV testing for HIV diagnosis as recommended by the World Health Organization (WHO) (WHO, 2001) given the test advantages of low cost and rapid results while requiring no instrumentation, refrigeration or electricity, with just minimal training. In addition, there is considerable evidence that the sensitivity and specificity of HIV rapid tests are comparable to or better than $3^{\text {rd }}$ generation enzyme immunoassays for the detection of HIV antibodies, particularly when used in combination as with dual rapid testing algorithms (Aidoo et al., 2001, WHO, 2004, Arthur et al., 2005, Branson, 2000).

HIV sero-incidence in sub-Saharan Africa among pregnant women has ranged from 1.3 per 100 persons years to 5.2 per 100 person years during pregnancy through the post-partum period (Mbizvo et al., 2001, Gray et al., 2005, Rehle et al., 2007, Lu et al., 2009). Further, in high risk populations, such as STD clinics in sub-Saharan Africa, a substantial number of subjects with AHI have been detected (Pilcher et al., 2004). In order to provide needed data on HIV infection and AHI prevalence in the sub-Saharan African PMTCT setting, we present findings from a cross-sectional study on the prevalence of AHI in pregnant women in Malawi.

\section{Materials and Methods}

From December 2000 to June 2004, 3825 pregnant women were enrolled into a cohort study at Queen Elizabeth Central Hospital (QECH), the main tertiary referral hospital in southern 
Malawi (Mwapasa et al., 2004). More detailed methods for recruitment and enrollment of participants in the cohort study are described elsewhere (Mwapasa et al., 2004). Pregnant women admitted to the QECH antenatal ward before the onset of active labor who met eligibility criteria and provided informed consent were enrolled. All participants received HIV pre-test counseling followed by blood collection for HIV and hemoglobin testing.

HIV status was determined by dual testing defined as the use of two simultaneous HIV rapid tests, Determine HIV-1/2 Rapid Test (Abbott Laboratories, Illinois, USA) and the SeroCard HIV-1/2 Rapid Test (Trinity Biotech, Co Wicklow, Eire), or Determine and HIVSPOT HIV-1/2 Rapid Test (Genelabs Diagnostics, Singapore). Discordant results were resolved with a third, alternative rapid test on a subsequent sample. Post-test HIV counseling was performed and demographic and medical information, as well as maternal and infant morbidity data were documented using standardized questionnaires. HIV-infected women and their infants received nevirapine according to the HIVNET 012 protocol.

For the current analysis, 2327 anonymized, available stored specimens from participants with negative HIV rapid testing results were evaluated for AHI at the University of North Carolina at Chapel Hill labs. Individual antibody-negative specimens were manually pooled with a pyramid-type 2 stage pooling algorithm, using an initial 10:1 pooling of 100ul aliquots from each specimen, followed by a second 5:1 pooling of aliquots from each 10-specimen pool to yield a master pool containing sample from 50 individuals. Master pools were screened for HIV RNA using the ultrasensitive Roche RNA assay with a lower limit of sensitivity of 50 copies $/ \mathrm{mL}$. Only 10 -specimen pools from reactive master pools and individual specimens from reactive 10-specimen pools underwent further HIV RNA testing. Specimens from the master pool with detectable HIV RNA underwent individual testing for viral load with the Roche Monitor assay, version 1.5 (Branchberg, NJ) with a lower detection limit of 400 copies $/ \mathrm{mL}$. All HIV RNA positive specimens were tested for HIV antibodies by Western Blot (Genetic Systems HIV-1 Western Blot. Bio-Rad, Hercules, CA) on stored plasma. AHI was defined as negative or indeterminate rapid HIV test results, a negative or indeterminate Western Blot, and a positive HIV RNA test. Participants with AHI were tested for herpes simplex virus type 2 (HSV-2) using the FDA-approved HerpeSelect ${ }^{\circledR}$ gG-2 ELISA (Focus Diagnostics, Cypress, $\mathrm{CA})$ at the UNC Laboratory.

Data were entered into Microsoft Access and analyzed in STATA, version 8.2 (StataCorp, College Station, Texas). The database for the parent study (Mwapasa et al., 2004) was stripped of all personal identifiers. Prevalence of established HIV and AHI were determined. The study was approved by the Malawi College of Medicine Research and Ethics Committee and the institutional review board at the University of North Carolina at Chapel Hill.

\section{Results}

3825 pregnant Malawian women were enrolled and screened for HIV. Median age of participants was 22 years of age (IQR: 19-26). The majority or 3467 (90.6\%) were married, $3023(79.0 \%)$ were unemployed, and 1401 (36.6\%) of participants were primigravid. HIV status was determined with two different rapid tests (dual testing), and indicated that 1155 $(30.2 \%)$ of women were HIV positive, 4 were indeterminate (because only one rapid test was performed), and 2666 (69.7\%) were HIV negative. Notably, of the $1155 \mathrm{HIV}$ positive pregnant women, only $66(5.7 \%)$ reported a previous diagnosis of HIV despite report of prenatal care in all but $5(0.43 \%)$ of women.

A consecutive sample using $583(50.5 \%)$ specimens from the 1155 rapid test positive women were retrospectively tested for HIV RNA. Of these, 553 (94.9\%) were HIV RNA positive, and $30(5.1 \%)$ were HIV RNA negative. Western blot testing was performed on the 30 rapid test 
positive but HIV RNA negative samples, and revealed that 6 were western blot negative, 5 were indeterminate and 19 were positive; reflecting 11 false positive results by rapid testing (see Figure 1) if Western blot testing is considered the gold standard.

Of the 2666 antibody negative pregnant women, 2327 (87.3\%) enrollment samples were available for additional HIV testing for AHI. Eleven subjects who were negative on dual rapid testing had detectable HIV RNA on pooling. Western blot testing for these 11 subjects revealed that six had established HIV infection, indicating false negative rapid test results. The median VL for these participants was 83,759 copies/mL (IQR: $10,816-124,360$ ). Of the remaining 2321 seronegative pregnant women, $5(0.21 \%)$ (95\% CI: $0.03,0.40 \%)$ had detectable plasma HIV RNA suggesting AHI. Overall, the sensitivity of dual rapid testing to detect HIV was 99.0\% and specificity was $98.7 \%$, with HIV RNA testing considered the gold standard. A similar result was found when additional Western blot results were used to assess test performance indicating a sensitivity of $99.1 \%$ and specificity of $99.5 \%$, respectively (see Figure 2).

Among the five acutely infected pregnant women, median age was 20 years (range 17-35). Four of five (80.0\%) acutely infected women were married, $3(60.0 \%)$ were primigravids, only one had no formal education, and none were employed. Three of the five $(60.0 \%)$ pregnant women with AHI were positive for HSV-2, but none had a history of tuberculosis, a prior STD or active syphilis. One subject with AHI was diagnosed with malaria at the time of study enrollment. One participant with AHI at enrollment reported a fever in the week preceding delivery, and 4 reported headache and generalized body pain in the same period. Three of five women with AHI had a viral load of greater than 1 million copies/mL (range 283,340 copies/ $\mathrm{mL}$ to $17,627,630$ copies $/ \mathrm{mL}$ ). Other than the very high levels of HIV RNA among these 3 women with AHI, there were no other clear baseline characteristics which distinguished cases of AHI compared with the remainder of the cohort.

As expected the median viral load for the subjects with AHI was very high at 1,324,766 copies/ mL (IQR: 385,875 - 6,887,916), compared with a median VL of 35,537 copies/mL (IQR: 9958 - 109,779) for 589 women with established HIV infection on whom HIV RNA results were available. The median estimated gestational age at the time of study enrollment and the date of detection of acute HIV infection was 36 weeks (range $31-44$ ). No data from infants born to mothers with AHI is available.

\section{Discussion}

There have been a very limited number of studies of incident HIV infection in pregnant women (Mbizvo et al., 2001, Gray et al., 2005, Lu et al., 2009), and only one prior attempt to identify the subset of women with acute infection in the US (Patterson et al., 2007). Although the prevalence of AHI $(0.21 \%)$ in this study population of pregnant Malawian women was low, this study likely underestimates the true AHI prevalence in this high HIV prevalence population since most women underwent HIV testing only in their third trimester. Thus, AHI (associated with very high viral loads) was likely missed at an earlier time point during pregnancy among many women in this high prevalence population. As might be expected, AHI was four times higher in Malawi than in a study of seronegative pregnant women in the US (Patterson et al., 2007). The risk of HIV during pregnancy reflects unprotected intercourse among couples which is likely the norm. In addition, hormonal changes associated with pregnancy may increase susceptibility to HIV infection (Brabin, 2002). A variety of other risk factors have been shown to increase HIV acquisition, particularly HSV-2 infection (Wald and Link, 2002), regardless of whether individuals are symptomatic; three out of five women with AHI in this study had chronic HSV-2 infection. 
Maternal-fetal transmission of HIV has been independently associated with higher HIV viral load (John et al., 2001) and genital tract DNA (John et al., 2001), as well as genital ulcer disease (GUD) (John et al., 2001). Prior work in this cohort also revealed that CCR5 polymorphisms (Tkachuk et al., 2001), maternal-fetal microtransfusions (Kwiek et al., 2006, Kwiek et al., 2008) and syphilis (Mwapasa et al., 2006) were risk factors for MTCT. Maternal viral load has been shown to increase the risk of both in utero and intrapartum transmission (Mock et al., 1999). Since the highest viral loads in the blood and the genital tract are observed during the first few weeks of HIV infection (Pilcher et al., 2001), concern for in utero and intrapartum transmission of HIV during this phase seems well justified. A single prospective study reported no difference in vertical transmission between women who seroconverted during pregnancy and those who tested positive at their initial antenatal visit (Roongpisuthipong et al., 2001). However, in the latter study median viral loads were similar in the two groups at delivery $(17,505$ and 20,845 copies/ml, respectively; $p=.80)$, suggesting that few women were acutely infected near the peripartum period, when risk is highest. In contrast, the high median viral load of 1,324,766 copies/mL among women with AHI in the third trimester in this study might be anticipated to increase the risk for HIV transmission. However, the infants born to women with AHI in this study were not available for study.

Dual rapid testing performed better for HIV screening in this study than recently reported in a Ugandan trial, which reported a sensitivity of $97.7 \%$ and a specificity of $94.1 \%$ (Gray et al., 2007). Combining all test results available we observed a sensitivity range of 99.0 to $99.1 \%$ and a specificity range of 98.7 to $99.5 \%$ for the detection of HIV, including AHI. Our findings indicate that the simultaneous use of dual rapid tests was effective in detecting HIV infection. However, 11 HIV infected women with AHI or false negative rapid tests were not detected and could not benefit from antiretroviral therapy to prevent HIV MTCT.

There are a number of limitations to our study. First, the retrospective laboratory methods of AHI detection limited our ability to provide information on infants of AHI patients and HIVinfected women in the study. The lack of outcome data for infants limits drawing any conclusions on the clinical significance of testing and providing PMTCT to pregnant women with AHI. Second, this study was conducted in an area of high HIV prevalence, possibly limiting the applicability of these data to other study populations. Third, the use of two seronegative tests as part of the AHI definition will fail to detect seropositive individuals with early HIV infection who are also likely to have high HIV RNA levels, and are likely at increased risk for vertical transmission. The narrow window of seronegativity for AHI with current rapid tests may partially explain the discrepancy between rapid tests and western blot results demonstrated in Figure 1.

This is the first time cross sectional screening for AHI has been applied to pregnant women in sub-Saharan Africa. However, our data are consistent with several studies in which additional HIV cases were detected by testing for HIV virus in seronegative subjects (Pilcher et al., 2004). This approach has the potential advantage of allowing the "real-time" detection of subjects and the immediate provision of treatment and prevention interventions. However, given the small number of cases detected and the lack of proof of benefit(s) to mothers and infants, such screening in this setting remains experimental. However, it is clear that pregnant women and their spouses (both HIV positive and negative) need counseling about safer sex and the risk and dangers of acquiring HIV during pregnancy. In addition, our data support guidelines which recommend repeat antibody HIV testing at delivery despite prior negative results (Branson et al., 2006, Lu et al., 2009). 


\section{Acknowledgments}

We would like to acknowledge and thank Priya Goshi Melissa Kerkau and Amy Loftis who performed the HIV RNA assays, Robert Krysiak and Marcia Hobbs who performed the HerpeSelect ${ }^{\circledR}$ gG-2 serological tests, as well as Ebbie Chalaluka, Debbie Kamwendo, Malcolm Molyneux, Stephen Rogerson, Eyob Tadesse and Rebecca Zeitlin for their contributions to this work.

Sponsorship: Supported by NIH grant \# AI 49084, the NIH-FIC grant \# 5 D43 TW00908 and the Center for AIDS Research at the University of North Carolina (5 P30 AI50410). Dr. Gay has been supported by a Centers for Disease Control and Prevention Association of Teachers of Preventive Medicine Fellowship and National institutes of Health Training Grant (T32AI07151).

\section{REFERENCES}

Aidoo S, Ampofo WK, Brandful JA, Nuvor SV, Ansah JK, Nii-Trebi N, Barnor JS, Apeagyei F, Sata T, Ofori-Adjei D, Ishikawa K. Suitability of a rapid immunochromatographic test for detection of antibodies to human immunodeficiency virus in Ghana, West Africa. J Clin Microbiol 2001;39:25722575. [PubMed: 11427570]

Arthur GR, Ngatia G, Rachier C, Mutemi R, Odhiambo J, Gilks CF. The role for government health centers in provision of same-day voluntary HIV counseling and testing in Kenya. J Acquir Immune Defic Syndr 2005;40:329-335. [PubMed: 16249708]

Brabin L. Interactions of the female hormonal environment, susceptibility to viral infections, and disease progression. AIDS Patient Care STDS 2002;16:211-221. [PubMed: 12055029]

Branson BM. Rapid tests for HIV antibody. AIDS Rev 2000;2:76-83.

Branson BM, Handsfield HH, Lampe MA, Janssen RS, Taylor AW, Lyss SB, Clark JE. Revised recommendations for HIV testing of adults, adolescents, and pregnant women in health-care settings. MMWR Recomm Rep 2006;55:1-17. quiz CE11-14. [PubMed: 16988643]

Gray RH, Li X, Kigozi G, Serwadda D, Brahmbhatt H, Wabwire-Mangen F, Nalugoda F, Kiddugavu M, Sewankambo N, Quinn TC, Reynolds SJ, Wawer MJ. Increased risk of incident HIV during pregnancy in Rakai, Uganda: a prospective study. Lancet 2005;366:1182-1188. [PubMed: 16198767]

Gray RH, Makumbi F, Serwadda D, Lutalo T, Nalugoda F, Opendi P, Kigozi G, Reynolds SJ, Sewankambo NK, Wawer MJ. Limitations of rapid HIV-1 tests during screening for trials in Uganda: diagnostic test accuracy study. BMJ 2007;335:188. [PubMed: 17545184]

John GC, Kreiss J. Mother-to-child transmission of human immunodeficiency virus type 1. Epidemiol Rev 1996;18:149-157. [PubMed: 9021309]

John GC, Nduati RW, Mbori-Ngacha DA, Richardson BA, Panteleeff D, Mwatha A, Overbaugh J, Bwayo J, Ndinya-Achola JO, Kreiss JK. Correlates of mother-to-child human immunodeficiency virus type 1 (HIV-1) transmission: association with maternal plasma HIV-1 RNA load, genital HIV-1 DNA shedding, and breast infections. J Infect Dis 2001;183:206-212. [PubMed: 11120927]

Khouri YF, McIntosh K, Cavacini L, Posner M, Pagano M, Tuomala R, Marasco WA. Vertical Transmission of HIV-1. Correlation with maternal viral load and plasma levels of CD4 binding site anti-gp120 antibodies. J Clin Invest 1995;95:732-737. [PubMed: 7860754]

Kwiek JJ, Arney LA, Harawa V, Pedersen B, Mwapasa V, Rogerson SJ, Meshnick SR. Maternal-fetal DNA admixture is associated with intrapartum mother-to-child transmission of HIV-1 in Blantyre, Malawi. J Infect Dis 2008;197:1378-1381. [PubMed: 18444794]

Kwiek JJ, Mwapasa V, Milner DA Jr. Alker AP, Miller WC, Tadesse E, Molyneux ME, Rogerson SJ, Meshnick SR. Maternal-fetal microtransfusions and HIV-1 mother-to-child transmission in Malawi. PLoS Med 2006;3:e10. [PubMed: 16287342]

Lu, L.; Legwaila, K.; Motswere, C.; Smit, M.; Jimbo, W.; Creek, T. HIV Incidence in pregnancy and the first post-partum year and implications for PMTCT programs, Francistown, Botswana, 2008, abstract 91; 16th Conference on Retroviruses and Opportunistic Infections; Montreal, Canada. 2009;

Mbizvo MT, Kasule J, Mahomed K, Nathoo K. HIV-1 seroconversion incidence following pregnancy and delivery among women seronegative at recruitment in Harare, Zimbabwe. Cent Afr J Med 2001;47:115-118. [PubMed: 11921668]

Mock PA, Shaffer N, Bhadrakom C, Siriwasin W, Chotpitayasunondh T, Chearskul S, Young NL, Roongpisuthipong A, Chinayon P, Kalish ML, Parekh B, Mastro TD, Bangkok Collaborative 
Perinatal HIV Transmission Study Group. Maternal viral load and timing of mother-to-child HIV transmission, Bangkok, Thailand. AIDS 1999;13:407-414. [PubMed: 10199232]

Mwapasa V, Rogerson SJ, Kwiek JJ, Wilson PE, Milner D, Molyneux ME, Kamwendo DD, Tadesse E, Chaluluka E, Meshnick SR. Maternal syphilis infection is associated with increased risk of motherto-child transmission of HIV in Malawi. Aids 2006;20:1869-1877. [PubMed: 16954728]

Mwapasa V, Rogerson SJ, Molyneux ME, Abrams ET, Kamwendo DD, Lema VM, Tadesse E, Chaluluka E, Wilson PE, Meshnick SR. The effect of Plasmodium falciparum malaria on peripheral and placental HIV-1 RNA concentrations in pregnant Malawian women. AIDS 2004;18:1051-1059. [PubMed: 15096809]

Patterson KB, Leone PA, Fiscus SA, Kuruc J, McCoy SI, Wolf L, Foust E, Williams D, Eron JJ, Pilcher CD. Frequent detection of acute HIV infection in pregnant women. AIDS 2007;21:2303-2308. [PubMed: 18090278]

Pilcher CD, Price MA, Hoffman IF, Galvin S, Martinson FE, Kazembe PN, Eron JJ, Miller WC, Fiscus SA, Cohen MS. Frequent detection of acute primary HIV infection in men in Malawi. AIDS 2004;18:517-524. [PubMed: 15090805]

Pilcher CD, Shugars DC, Fiscus SA, Miller WC, Menezes P, Giner J, Dean B, Robertson K, Hart CE, Lennox JL, Eron JJ Jr. Hicks CB. HIV in body fluids during primary HIV infection: implications for pathogenesis, treatment and public health. AIDS 2001;15:837-845. [PubMed: 11399956]

Rehle T, Shisana O, Pillay V, Zuma K, Puren A, Parker W. National HIV incidence measures--new insights into the South African epidemic. S Afr Med J 2007;97:194-199. [PubMed: 17440667]

Roongpisuthipong A, Siriwasin W, Simonds RJ, Sangtaweesin V, Vanprapar N, Wasi C, Singhanati S, Mock P, Young N, Parekh B, Mastro TD, Shaffer N. HIV seroconversion during pregnancy and risk for mother-to-infant transmission. J Acquir Immune Defic Syndr 2001;26:348-351. [PubMed: 11317077]

The Working Group on MTCT of HIV. Rates of mother-to-child transmission of HIV-1 in Africa, America and Europe: results of 13 perinatal studies. Journal of Acquired Immune Deficiency Syndrome and Human Retrovirology 1995;8:506-510.

Tkachuk AN, Moormann AM, Poore JA, Rochford RA, Chensue SW, Mwapasa V, Meshnick SR. Malaria enhances expression of CC chemokine receptor 5 on placental macrophages. J Infect Dis 2001;183:967-972. [PubMed: 11237815]

Tuomala RE, O’Driscoll PT, Bremer JW, Jennings C, Xu C, Read JS, Matzen E, Landay A, Zorrilla C, Blattner W, Charurat M, Anderson DJ. Cell-associated genital tract virus and vertical transmission of human immunodeficiency virus type 1 in antiretroviral-experienced women. J Infect Dis 2003;187:375-384. [PubMed: 12552421]

Volmink J, Siegfried N, van der Merwe L, Brocklehurst P. Antiretrovirals for reducing the risk of motherto-child transmission of HIV infection. Cochrane Database Syst Rev. 2007 CD003510.

Wald A, Link K. Risk of human immunodeficiency virus infection in herpes simplex virus type 2seropositive persons: a meta-analysis. J Infect Dis 2002;185:45-52. [PubMed: 11756980]

WHO. Guidelines for using HIV testing technologies in surveillance. World Health Organization and Joint United Nations Programme on HIV/AIDs; 2001.

WHO. HIV Assays: Operational characteristics. 2004.

WHO. Scaling up HIV services for women and children. 2008. 


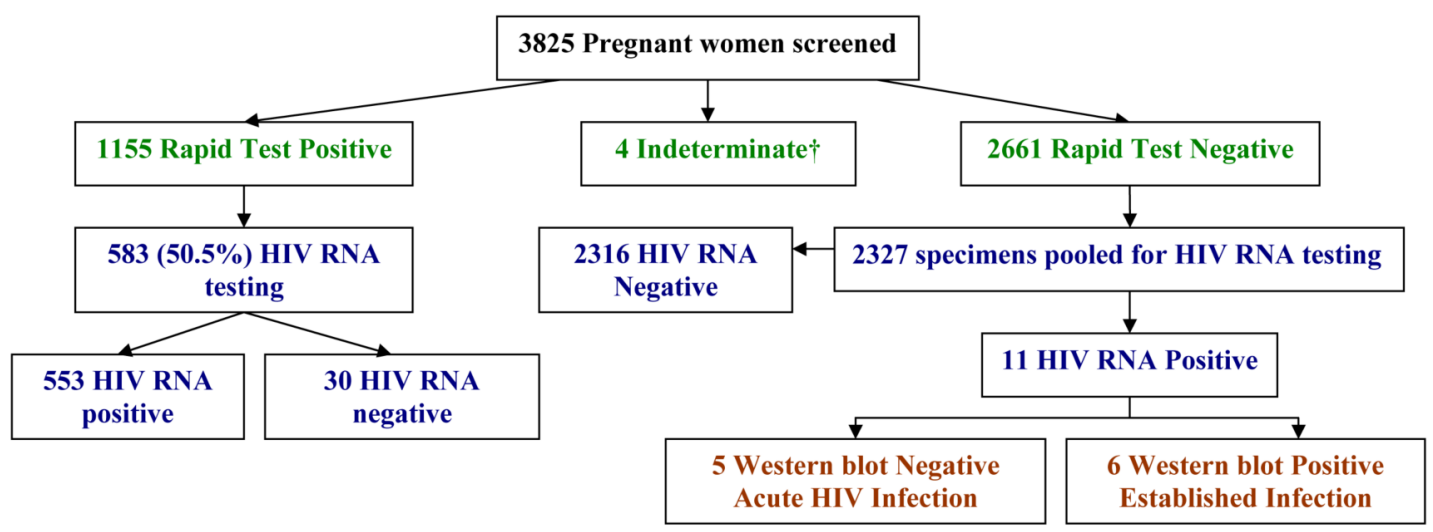

Figure 1.

HIV testing results from screening and retrospective detection of acute HIV infection.

†Only one rapid test performed. 


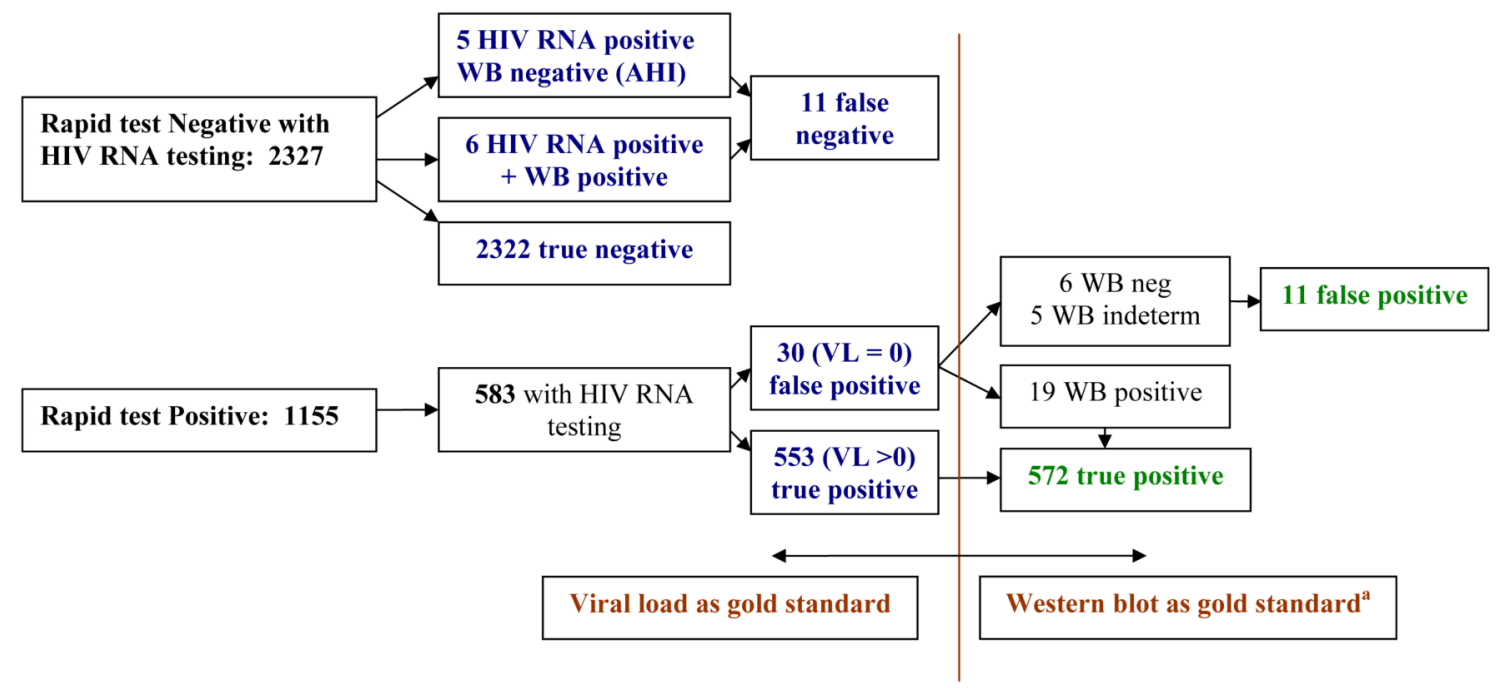

Figure 2.

HIV testing results applied to sensitivity and specificity calculations with viral load versus western blot as the gold standard.

${ }^{a}$ Not all samples underwent Western blot testing, precluding use of Western blot as the gold standard in sensitivity and specificity calculation. 